\title{
The Prevalence of Systemic Rheumatic Diseases Among Breast Cancer Patients and Its Relationship With Survival
}

\author{
Veli SUNAR (1)', Öztürk ATEŞ(1², Alma KORCALI ASLAN(1)'

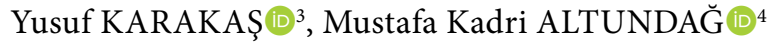 \\ ${ }^{1}$ Department of Medical Oncology, Hacettepe University Medical Faculty, Ankara, Turkey \\ ${ }^{2}$ Department of Medical Oncology, Abdurrahman Yurtaslan Training and Research Hospital, Ankara, Turkey \\ ${ }^{3}$ Department of Medical Oncology, Hakkari Devlet Hastanesi, Hakkari, Turkey \\ ${ }^{4}$ Department of Medical Oncology, MKA Breast Cancer Clinic, Ankara, Turkey
}

\begin{abstract}
Objectives: This study aims to investigate the prevalence of systemic rheumatic diseases (SRDs) among patients with breast cancer (BC) and to identify the clinicopathological characteristics of these patients.

Patients and methods: A total of 3,744 female patients with BC (mean age 49 \pm 11.7 years; range, 18 to 92 years) followed in Hacettepe University Faculty of Medicine, Medical Oncology Department between January 2006 and December 2015 were retrospectively assessed. Patients with or without SRD were compared in terms of clinicopathological features including age, menopausal state, smoking status, body mass index (BMI), age of menarche, age at first labor, and number of children. The groups were also evaluated regarding tumor grade, stage, estrogen receptor and progesterone receptor expression, human epidermal growth factor receptor 2 overexpression, and survival.

Results: Of the patients analyzed, $68(1.81 \%)$ had concomitant SRD. Among these patients, 33 (48.6\%) had rheumatoid arthritis, eight (11.8\%) had familial Mediterranean fever, eight (11.8\%) had Behçet's disease, four (5.8\%) had Sjögren's syndrome, four (5.8\%) had systemic lupus erythematosus, six $(8.8 \%)$ had ankylosing spondylitis, three $(4.4 \%)$ had systemic sclerosis, one (1.4\%) had polymyositis, and one (1.4\%) had temporal arteritis. The groups with or without SRDs were similar in terms of age, smoking status, BMI, menopausal state, breast feeding duration, age at menarche and first birth. Stage 1 and 2 BC was more prevalent in SRD patients ( $74.6 \%$ vs. $64.5 \%, p=0.018)$. The rate to receive chemotherapy was significantly lower in patients with SRD. However, there was no significant difference in five-year overall survival rates between patients with or without SRD.

Conclusion: Among patients with BC, $1.81 \%$ had concomitant SRD. These patients were diagnosed at early stages and given chemotherapy less frequently. However, they had similar survival rates compared to those without SRDs.

Keywords: Breast cancer, prevalence, survival, systemic rheumatic diseases.
\end{abstract}

Breast cancer $(\mathrm{BC})$ is the most common malignancy among females. ${ }^{1}$ There are many predisposing risk factors for $\mathrm{BC}$ such as tumor syndromes including BRCA1/BRCA2 mutations, family history, history of atypical hyperplasia on biopsy, early menarche, etc. However, known factors account only for $45-55 \%$ of the cases. ${ }^{2}$

The relationship between $\mathrm{BC}$ and systemic rheumatic diseases (SRDs) has not been clarified yet. There is a strong link between pro-inflammatory cytokines, tumor initiation, and tumor survival. ${ }^{3}$ These autoimmune conditions have been linked to increased risk of lymphoid malignancies and some other site-specific malignancies ${ }^{4}$ Cytokine and chemokine dysregulation is substantial in pathogenesis of both SRD and cancer. Cytokines and chemokines conduct the inflammatory process and direct angiogenesis, proliferation, apoptosis, and invasion which also take part in tumorigenesis and metastasis. ${ }^{5}$

Received: January 03, 2018 Accepted: May 07, 2018 Published online: August 16, 2018

Correspondence: Veli Sunar, MD. Hacettepe Üniversitesi Tıp Fakültesi Medikal Onkoloji Bilim Dalı, 06230 Altındağ, Ankara, Turkey. Tel: +90312 - 3065436 e-mail: velisunar@gmail.com 
Moreover, some cancers may cause rheumatologic symptoms and present with joint, muscle, or soft tissue involvement. ${ }^{6,7}$ The malignancies with most frequent musculoskeletal implications are leukemias, lymphomas, and paraneoplastic syndromes as a component of solid tumors. Besides, musculoskeletal or connective tissue diseases including arthralgia and arthritis may emerge as a result of cancer treatment. Aromatase inhibitors and immune checkpoint inhibitors including ipilimumab, pembrolizumab, and atezolizumab are among the most commonly accused medications latter of which is linked to immune-related adverse events such as inflammatory arthritis, sicca syndrome, vasculitis, inflammatory myopathy, eosinophilic fasciitis, and lupus nephritis. ${ }^{7,8}$

Study results regarding the prevalence of cancer risk in autoimmune conditions are conflicting. In a recent meta-analysis, patients with rheumatoid arthritis (RA) were noted to be at an increased risk of lung cancer and lymphoma compared to the general population. ${ }^{9}$ In a population-based cohort study from South Australia investigating cancer risk in systemic sclerosis (SSc) patients, the standardized incidence ratios (SIR) for all cancers among the subgroups with diffuse systemic sclerosis $(\mathrm{SIR}=2.73)$ and limited systemic sclerosis $(\mathrm{SIR}=1.85)$ were significantly increased. ${ }^{10}$ An international cohort study to evaluate the incidence of cancer among systemic lupus erythematosus (SLE) patients also revealed an increased risk of cancer. The SIR estimate for all cancers combined, for all hematologic malignancies, for non-Hodgkin's lymphoma, and for lung cancer was $1.15,2.75$, 3.64 , and 1.37 , respectively. ${ }^{11}$

However, data regarding the prevalence of SRDs in cancer patients are relatively scarce. Therefore, in this study, we aimed to investigate the prevalence of SRDs among patients with $\mathrm{BC}$ and to identify the clinicopathological characteristics of these patients.

\section{PATIENTS AND METHODS}

Medical records of 4,110 patients with BC followed-up in Hacettepe University Faculty of Medicine, Medical Oncology Department between January 2006 and December 2015 were retrospectively examined. Of the patients evaluated, 3,744 female patients (mean age $49 \pm 11.7$ years; range, 18 to 92 years) were included in this study whose clinicopathological data were complete and pathological analyses were performed in Hacettepe University Faculty of Medicine, Pathology Department. The remaining 366 patients whose pathological analyses were performed in other centers and whose clinical data were missing were excluded. Estrogen receptor (ER), progesterone receptor (PR) and human epidermal growth factor receptor 2 (HER2) statuses were assessed by immunohistochemical analyses. ER/PR status was assumed positive for $\geq 1 \%$ nuclear staining. HER2 overexpression was assumed positive for +3 , negative for +1 , and confirmed with fluorescence in situ hybridization (FISH) for +2 . It was assumed positive if HER2 amplification was present in the FISH test. The study was conducted in accordance with the principles of the Declaration of Helsinki.

The presence of a SRD was based on patients' claims and medical records. However, patients with previous history of acute rheumatic fever in childhood without established current consequences or drug use were not included. Patients were divided into two groups as those with or without SRD. Two groups were compared in terms of age, body mass index (BMI), age at menarche, age at first labor, number of children, and breastfeeding duration. The groups were also evaluated regarding smoking status, menopausal status, oral contraceptive (OC) and hormone replacement treatment (HRT) use, histologic grade, stage, histological subtype, ER/PR status, HER2 overexpression, lymphovascular invasion (LVI),

Table 1. Distribution of systemic rheumatic diseases among breast cancer patients $(n=68)$

\begin{tabular}{lcc}
\hline & $\mathrm{n}$ & $\%$ \\
\hline Rheumatoid arthritis & 33 & 48.6 \\
Familial Mediterranean fever & 8 & 11.8 \\
Behçet's disease & 8 & 11.8 \\
Ankylosing spondylitis & 6 & 8.8 \\
Sjögren's syndrome & 4 & 5.8 \\
Systemic lupus erythematosus & 4 & 5.8 \\
Systemic sclerosis & 3 & 4.4 \\
Temporal arteritis & 1 & 1.4 \\
Polymyositis & 1 & 1.4 \\
\hline
\end{tabular}




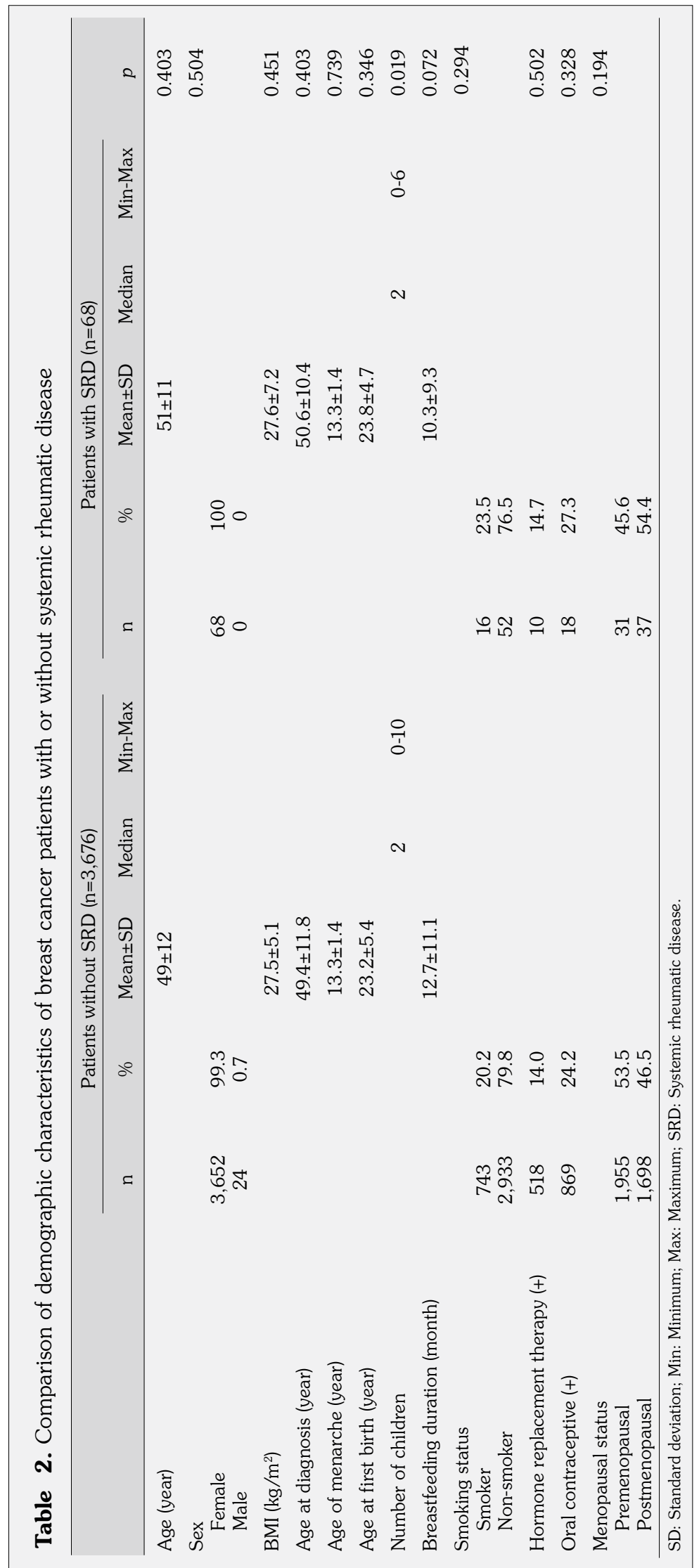


perineural invasion (PNI), extracapsular extension (ECE), treatments, and survival.

\section{Statistical analysis}

PASW version 18.0 (SPSS Inc., Chicago, IL., USA) was used for statistical analysis. Chi-square test was used for comparison of categorical variables and Mann-Whitney $U$ test or Student's t-test for numerical variables. Kaplan-Meier analysis was used for survival analysis and log-rank test for comparison of outcomes. A $p$ value $<0.05$ was considered as statistically significant.

\section{RESULTS}

Among 3,744 BC patients analyzed, 1.81\% $(n=68)$ had a diagnosis of SRD. Among these patients, 33 (48.6\%) had RA, eight (11.8\%) had familial Mediterranean fever, eight (11.8\%) had Behçet's disease, four (5.8\%) had Sjögren's syndrome (SS), four (5.8\%) had SLE, six (8.8\%) had ankylosing spondylitis, three (4.4\%) had SSc, one (1.4\%) had polymyositis, and one (1.4\%) had temporal arteritis (Table 1).

The median age, smoking status, BMI, menopausal status, rate of HRT and OC use, breastfeeding duration, age at menarche and first birth were similar between patients with or without SRD. The number of children was significantly higher in BC patients without SRD $(p=0.019)$ (Table 2). Tumor histologic grade, HER2 overexpression, LVI, PNI, and ECE were also similar between groups. Although not statistically significant, ER/PR positivity was more common among patients with SRD. Stage 1 and 2 tumors were significantly more common in $\mathrm{BC}$ patients with SRD (74.6\% vs. $64.5 \%, p=0.018)$. The rate to receive chemotherapy was significantly lower in BC patients with SRD $(62.1 \%$ vs. 76.0\%, $p=0.009$ ) (Table 3). However, five-year overall survival rates were similar between the groups $(87.2 \%$ vs. $87.7 \%$ in SRD and non-SRD patients, respectively; $p=0.87$ ). There was also no significant difference in terms of five-year disease-free survival rate between patients with

Table 3. Comparison of clinicopathological characteristics of breast cancer patients with or without systemic rheumatic disease

\begin{tabular}{|c|c|c|c|c|c|}
\hline & \multicolumn{2}{|c|}{ Patients without SRD $(n=3,676)$} & \multicolumn{2}{|c|}{ Patients with SRD $(n=68)$} & \multirow[b]{2}{*}{$p$} \\
\hline & $\mathrm{n}$ & $\%$ & $\mathrm{n}$ & $\%$ & \\
\hline Grade & & & & & 0.518 \\
\hline 1 & 392 & 12.3 & 10 & 16.9 & \\
\hline 2 & 1,455 & 45.7 & 27 & 45.8 & \\
\hline 3 & 1,338 & 42.0 & 22 & 37.8 & \\
\hline Stage & & & & & 0.018 \\
\hline 1 and 2 & 2,315 & 64.5 & 50 & 74.6 & \\
\hline 3 and 4 & 1,274 & 35.5 & 17 & 25.4 & \\
\hline \multicolumn{6}{|l|}{ Histological type } \\
\hline Lobular histology (pure-mixed) & 622 & 17.1 & 18 & 26.8 & 0.036 \\
\hline Invasive ductal carcinoma & 2,670 & 73.3 & 44 & 65.7 & 0.128 \\
\hline Other & 349 & 9.6 & 5 & 7.5 & 0.128 \\
\hline \multicolumn{6}{|l|}{ Estrogen receptor/progesterone receptor status } \\
\hline Estrogen receptor $(+)$ & 2,640 & 74.7 & 53 & 81.5 & 0.208 \\
\hline Progesterone receptor $(+)$ & 2,477 & 67.4 & 48 & 70.6 & 0.410 \\
\hline Human epidermal growth factor receptor 2-positive & 755 & 20.5 & 10 & 14.7 & 0.237 \\
\hline Lymphovascular invasion (+) & 1,018 & 27.6 & 14 & 20.6 & 0.194 \\
\hline Perineural invasion $(+)$ & 406 & 11.0 & 7 & 10.3 & 0.845 \\
\hline Extracapsular extension (+) & 452 & 12.3 & 5 & 7.4 & 0.217 \\
\hline Triple negative breast cancer & 423 & 11.9 & 6 & 9.2 & 0.503 \\
\hline Chemotherapy (+) & 2,765 & 76.0 & 41 & 62.1 & 0.009 \\
\hline Radiotherapy (+) & 2,614 & 72.4 & 42 & 63.6 & 0.078 \\
\hline Endocrine therapy (+) & 2,742 & 74.6 & 54 & 79.4 & 0.228 \\
\hline
\end{tabular}


or without SRD $(82.4 \%$ vs. $76.9 \%$, respectively; $\mathrm{p}=0.67$ ).

Among SRD patients, RA constituted the largest group. Therefore, we performed subgroup analysis for RA patients. Five-year overall survival rate of $\mathrm{BC}$ patients with $\mathrm{RA}$ was similar to BC patients without SRD $(80.5 \%$ vs. $87.7 \%$; $\mathrm{p}=0.44)$. Five-year disease-free survival rates were also similar between $\mathrm{BC}$ patients with $\mathrm{RA}$ and $\mathrm{BC}$ patients without SRD (77.3\% vs. 76.9\%; $\mathrm{p}=0.52)$.

Clinicopathological characteristics of $B C$ patients with $\mathrm{RA}$ and $\mathrm{BC}$ patients without $\mathrm{SRD}$ were compared. $\mathrm{BC}$ patients with $\mathrm{RA}$ were diagnosed more elderly $(54 \pm 11$ years in RA vs. $49 \pm 12$ years in non-SRD; $p=0.026)$ and often postmenopausal $(75.8 \%$ in RA vs. $46.2 \%$ in non-SRD; $p=0.001$ ) than $\mathrm{BC}$ patients without $\mathrm{SRD}$. The rate to receive chemotherapy was significantly lower in patients with RA than non-SRD patients $(54.5 \%$ in RA vs. $75.2 \%$ in non-SRD; $p=0.021$ ). Other clinicopathological characteristics were similar between $\mathrm{BC}$ patients with RA and BC patients without SRD.

\section{DISCUSSION}

Patients with SRD, including RA, SS, SLE, and idiopathic inflammatory myopathies, bear increased risk for developing certain malignancies. This risk is attributed to both underlying immunologic impairments of autoimmune diseases and exposure to immunomodulator medications. Pro-inflammatory cytokines such as tumor necrosis factor-alpha (TNF- $\alpha$ ), interleukin 1 (IL-1), IL-6, granulocytemacrophage colony-stimulating factor, and IL-8 are abundant in circulation, particularly in SRDs including SLE and RA. There is a relative insufficiency of anti-inflammatory cytokines such as IL-10, transforming growth factor-beta, IL-1 receptor antagonist to protect breast tissue from the chronic effect of these cytokines. ${ }^{3}$ The immune dysregulation may predispose the host to certain malignancies; however, the suppression of ongoing inflammatory response may paradoxically lower the risk for development of neoplasms. ${ }^{12}$ Also, pharmacologic therapy of SRDs such as alkylating agents, (chlorambucil and cyclophosphamide), or immunosuppressive and anti-inflammatory drugs (azathioprine, methotrexate) may contribute to the risk of malignancy development.

In the present study, we screened Turkish $\mathrm{BC}$ patients to evaluate the prevalence of SRDs. The prevalence we detected (1.8\%) may be lower than expected; however, this may be due to not including patients with certain diagnoses or current medications. The prevalence would have been higher if patients were included such as those with arthralgia or history of acute rheumatic fever, activity or sequelae status that could not be concluded from the medical records. As a matter of fact, studies reporting the prevalence of SRDs in the Turkish population are insufficient to a degree. Prevalence data to represent adult population are practically lacking for some SRD types. ${ }^{13}$ Therefore, it may be challenging to indicate whether a prevalence of $1.81 \%$ is high or low compared to the healthy population.

Similar studies to ours were reported in the literature. However, these generally evaluated the risk and prevalence of BC in SRD patients. In a study on an approximate of 200,000 patients with autoimmune diseases, $\mathrm{BC}$ risk was found to be lower with a SIR of $0.94 .^{14}$ Another study on $84,778 \mathrm{BC}$ cases reported that BC risk decreased in patients with RA and SLE. None of the other investigated SRDs were associated with BC risk. Furthermore, RA was inversely associated with both ER-positive and ER-negative $\mathrm{BC}$ risk. ${ }^{15}$

Estrogen synthesis and estrogen concentrations were shown to be higher in malignant breast tissue than normal. ${ }^{16,17}$ Cytokines are considered as important regulators of estrogen synthesis in breast tissues, and there is a model proposed for involvement of the immune system and cytokines in controlling the peripheral synthesis of estrogens. IL-6, which is also a cytokine targeted in RA treatment, has been identified as another factor with capacity of stimulating aromatase activity. ${ }^{18}$ Some studies indicate that stress or immunosuppression may alter the risk of developing $\mathrm{BC}$. The incidence of $\mathrm{BC}$ in kidney transplant patients having immunosuppressive therapy is $25 \%$ lower than the normal population. ${ }^{19}$ Immunosuppressive drugs hinder white blood cell production and the cytokine secretion of these cells. Therefore, lower amounts of cytokines would not stimulate estrogen synthesis adequately for tumor growth 
in breast tissue and may contribute to decreased incidence of $\mathrm{BC}$ in these patients. In another study, it was shown that plasma estrogen concentrations were substantially higher in male septic shock patients. Plasma estrone and estradiol levels were found to increase 13-fold and five-fold, respectively, in shock patients compared with normal subjects. ${ }^{20}$ Some studies have shown that estrogen concentration is higher in ER-positive BC tissue. ${ }^{21,22}$ Estrogen receptor status is of great significance because of its clinical implication. However, we did not observe any significant difference in ER/PR positivity between patients with or without SRD.

In the present study, stage 1 and 2 tumors were significantly more common in patients with SRD had than patients without SRD. A possible reason for this may be early diagnosis due to SRD patients' routine follow-ups for their rheumatic diseases. We consider that their regular visits to healthcare services and contacts with healthcare professionals may have enhanced their perception about screening programs. Another possible reason could be the effect of non-steroidal anti-inflammatory drugs SRD patients use. There are studies indicating that cyclooxygenase-2 expression is a negative prognostic factor and associated with poorer outcome in $\mathrm{BC}$ patients. ${ }^{23}$

Compatible with their lower stage tumors, patients with SRD were found to receive chemotherapy significantly less frequently compared to patients without SRD in the present study. The frequency of having radiotherapy was also lower among patients with SRD; however, the difference was not statistically significant.

In the present study, overall survival rate was similar between groups. Results of studies regarding survival are conflicting in the literature. In a population-based study from Great Britain, it was reported that survival due to a variety of cancer types decreased among patients with inflammatory arthritis compared to the general population. ${ }^{24}$ In a recent retrospective study on 122 colon, gastric, lung, and BC patients with several SRDs including RA, dermatomyositis/ polymyositis (DM/PM), SLE, SSc, patients with $\mathrm{RA}$ and $\mathrm{DM} / \mathrm{PM}$ were found to be associated with higher mortality in patients with lung cancer or BC. ${ }^{25}$ In another study from Sweden on $1,411,163$ cancer patients, patients with RA were noted to have worse prognosis, with hazard ratios of 1.29 and 1.31 for cause-specific and overall survival, respectively, compared to all cancer patients without RA. ${ }^{26}$ However, our study did not disclose any significant difference in terms of five-year overall survival and diseasefree survival between RA patients and patients without SRDs. A recent study analyzing data from 14 SLE cohorts to assess lung cancer risk according to demographic characteristics, drug exposure, smoking, and disease activity indicated a remarkable outcome that smoking might be the most significant modifiable lung cancer risk factor in SLE. ${ }^{27}$ However, we did not detect any statistical difference regarding smoking status between BC patients with or without SRDs.

To our knowledge, this is the first study to evaluate the prevalence of systemic rheumatic diseases in patients with BC in Turkish population. Nevertheless, a limitation of our study was the relatively low number of SRD patients. Another limitation was the lack of data regarding $\mathrm{SRD}$ patients' medications, course and severity. Also, due to heterogeneity of the SRDs identified in the analyzed group, we could not come to any conclusion on the exact prevalence of each SRD in $\mathrm{BC}$ patients. If each rheumatic disease was handled separately, we would have the possibility to declare whether the prevalence of these diseases was higher or lower than the normal population.

In conclusion, the prevalence of SRDs among $\mathrm{BC}$ patients in our center was 1.8\%. BC patients with SRD were diagnosed at earlier stages and given chemotherapy less frequently. However, we did not detect any significant difference regarding survival compared to BC patients without SRD.

\section{Declaration of conflicting interests}

The authors declared no conflicts of interest with respect to the authorship and/or publication of this article.

\section{Funding}

The authors received no financial support for the research and/or authorship of this article.

\section{REFERENCES}

1. Castaño Z, Tracy K, McAllister SS. The tumor macroenvironment and systemic regulation of breast cancer progression. Int J Dev Biol 2011;55:889-97. 
2. Willett $\mathrm{W}$. Nongenetic factors in the causation of breast cancer. In: Harris JR, Lippman ME, Morrow $\mathrm{M}$, Osborne $\mathrm{CK}$, editors. Diseases of the breast. Philadelphia: Lippincott Williams \& Wilkins; 2004. p. 223-76.

3. Feldmann M, Brennan FM, Maini RN. Role of cytokines in rheumatoid arthritis. Annu Rev Immunol 1996;14:397-440.

4. Molinelli E, Giuliodori K, Campanati A, Brisigotti $\mathrm{V}$, Offidani A. Coexistence of systemic lupus erythematosus, Hashimoto's thyroiditis, and bilateral breast cancer in the same patient: a random association? Acta Dermatovenerol Alp Pannonica Adriat 2015;24:55-7.

5. England BR, Sokolove J, Robinson WH, Thiele GM, Ganti AK, Sayles H, et al. Associations of circulating cytokines and chemokines with cancer mortality in men with rheumatoid arthritis. Arthritis Rheumatol 2016;68:2394-402.

6. Naschitz JE, Rosner I. Musculoskeletal syndromes associated with malignancy (excluding hypertrophic osteoarthropathy). Curr Opin Rheumatol 2008;20:100-5.

7. Gheita TA, Ezzat Y, Sayed S, El-Mardenly G, Hammam W. Musculoskeletal manifestations in patients with malignant disease. Clin Rheumatol 2010;29:181-8.

8. Cappelli LC, Shah AA, Bingham CO. Cancer immunotherapy-induced rheumatic diseases emerge as new clinical entities. RMD Open 2016;2:e000321.

9. Simon TA, Thompson A, Gandhi KK, Hochberg MC, Suissa S. Incidence of malignancy in adult patients with rheumatoid arthritis: a meta-analysis. Arthritis Res Ther 2015;17:212.

10. Hill CL, Nguyen AM, Roder D, Roberts-Thomson P. Risk of cancer in patients with scleroderma: a population based cohort study. Ann Rheum Dis 2003;62:728-31.

11. Bernatsky S, Boivin JF, Joseph L, Rajan R, Zoma A, Manzi S, et al. An international cohort study of cancer in systemic lupus erythematosus. Arthritis Rheum 2005;52:1481-90.

12. Balkwill F, Mantovani A. Inflammation and cancer: back to Virchow? Lancet 2001;357:539-45.

13. Akkoç N. Türkiye'de romatizmal hastalıkların epidemiyolojisi ve diğer ülkelerle karşılaştırılması. RAED Dergisi 2010;2:1-8.

14. Hemminki K, Liu X, Ji J, Försti A, Sundquist J, Sundquist $\mathrm{K}$. Effect of autoimmune diseases on risk and survival in female cancers. Gynecol Oncol 2012;127:180-5.

15. Gadalla SM, Amr S, Langenberg P, Baumgarten M, Davidson WF, Schairer C, et al. Breast cancer risk in elderly women with systemic autoimmune rheumatic diseases: a population-based case-control study. $\mathrm{Br} \mathrm{J}$ Cancer 2009;100:817-21.
16. Bonney RC, Reed MJ, Davidson K, Beranek PA, James VH. The relationship between 17 betahydroxysteroid dehydrogenase activity and oestrogen concentrations in human breast tumours and in normal breast tissue. Clin Endocrinol (Oxf) 1983;19:727-39.

17. Blankenstein MA, Maitimu-Smeele I, Donker GH, Daroszewski J, Milewicz A, Thijssen JH. On the significance of in situ production of oestrogens in human breast cancer tissue. J Steroid Biochem Mol Biol 1992;41:891-6.

18. Purohit A, Newman SP, Reed MJ. The role of cytokines in regulating estrogen synthesis: implications for the etiology of breast cancer. Breast Cancer Res 2002;4:65-9.

19. Stewart T, Tsai SC, Grayson H, Henderson R, Opelz G. Incidence of de-novo breast cancer in women chronically immunosuppressed after organ transplantation. Lancet 1995;346:796-8.

20. Christeff N, Benassayag C, Carli-Vielle C, Carli $A$, Nunez EA. Elevated oestrogen and reduced testosterone levels in the serum of male septic shock patients. J Steroid Biochem 1988;29:435-40.

21. Fishman J, Nisselbaum JS, Menendez-Botet CJ, Schwartz MK. Estrone and estradiol content in human breast tumors: relationship to estradiol receptors. J Steroid Biochem 1977;8:893-6.

22. Edery M, Goussard J, Dehennin L, Scholler R, Reiffsteck J, Drosdowsky MA. Endogenous oestradiol17beta concentration in breast tumours determined by mass fragmentography and by radioimmunoassay: relationship to receptor content. Eur $\mathrm{J}$ Cancer 1981;17:115-20.

23. Fornetti J, Jindal S, Middleton KA, Borges VF, Schedin P. Physiological COX-2 expression in breast epithelium associates with COX-2 levels in ductal carcinoma in situ and invasive breast cancer in young women. Am J Pathol 2014;184:1219-29.

24. Franklin J, Lunt M, Bunn D, Symmons D, Silman A. Influence of inflammatory polyarthritis on cancer incidence and survival: results from a community-based prospective study. Arthritis Rheum 2007;56:790-8.

25. Park JK, Yang JA, Ahn EY, Chang SH, Song YW, Curtis JR, et al. Survival rates of cancer patients with and without rheumatic disease: a retrospective cohort analysis. BMC Cancer 2016;16:381.

26. Ji J, Liu X, Sundquist K, Sundquist J. Survival of cancer in patients with rheumatoid arthritis: a followup study in Sweden of patients hospitalized with rheumatoid arthritis 1 year before diagnosis of cancer. Rheumatology (Oxford) 2011;50:1513-8.

27. Bernatsky S, Ramsey-Goldman R, Petri M, Urowitz MB, Gladman DD, Fortin PR, et al. Smoking Is the Most Significant Modifiable Lung Cancer Risk Factor in Systemic Lupus Erythematosus. nJ Rheumatol 2018;45:393-6. 